\title{
Recovery of germanium from leach solutions of fly ash using solvent extraction with various extractants
}

\author{
Hossein Kamran Haghighi ${ }^{\mathrm{a}}$, Mehdi Irannajad *a ${ }^{\mathrm{a}}$, Agustin Fortuny ${ }^{\mathrm{b}}$, Ana Maria Sastre ${ }^{\mathrm{c}}$ \\ ${ }^{a}$ Department of Mining and Metallurgical Engineering, Amirkabir University of Technology, Tehran, \\ Iran. \\ ${ }^{\mathrm{b}}$ Department of Chemical Engineering, Universitat Politècnica de Catalunya, EPSEVG, Av. Víctor \\ Balaguer s/n, 08800 Vilanova i la Geltrú, Spain. \\ ${ }^{c}$ Department of Chemical Engineering, Universitat Politècnica de Catalunya, ESTEIB, Av. Diagonal 647, \\ 08028 Barcelona, Spain. \\ * Corresponding author's email: iranajad@aut.ac.ir
}




\begin{abstract}
The solvent extraction of germanium and some heavy metals by commercial tri-octyl/decyl amine (Alamine 336), N-methyl-N, N-dioctyl chloride (Aliquat 336) and phosphine oxide (Cyanex 923) has been studied. In each extraction system, germanium was only extracted from a solution containing nickel, cadmium, cobalt, and zinc, which had a composition similar to gasification coal fly ash aqueous leach solutions. Under a comparable condition, the germanium extraction efficiency by the aforementioned extractants was in the order Aliquat 336>Alamine 336>Cyanex 923. The slope analysis method showed that 2 moles of Alamine 336 and Aliquat 336, as well as 4 moles of Cyanex 923, participated in the extraction of germanium. In amine extraction systems, tartaric acid was required as a complexant used to convert germanium to anionic species. As a result, the ratio of 2 (mole ration of tartaric acid to Ge) was required to complete anionic complexation. On the other hand, oxalic acid with a concentration of $0.1 \mathrm{M}$ was chosen as a proper solvated complexant in the Cyanex 923 system. $\mathrm{HCl}$ solutions with concentrations of 1 and $2 \mathrm{M}$ can properly strip germanium from the loaded Alamine 336 and Aliquat 336, respectively. In addition, $0.1 \mathrm{M} \mathrm{NaOH}$ was sufficient for germanium stripping from Cyanex 923. Consequently, it can be concluded that Aliquat 336 can be an economical and industry-friendly extractant for germanium solvent extraction from a mixed solution.
\end{abstract}

Keywords: Germanium; Alamine 336; Aliquat 336; Cyanex 923; Fly ashes 


\section{Introduction}

Germanium is a rare element, which does not occur in a specific ore body (Liu et al., 2017). It can be found as a sub-element in zinc, copper, aluminum, and coal fly ash (FA) resources (Arroyo et al., 2009; Harbuck et al., 1991). However, it has been reported that the main economic resources of germanium are zinc ores and coals (Depuydt et al., 2007; Nusen et al., 2015). Coal and its related products can be an important resource of germanium. The content of germanium in coal may be enriched several times in gasification coal fly ashes (GCFA). Among the elements existing in GCFA, germanium in the form of $\mathrm{GeO}_{2}$ and $\mathrm{GeS}_{2}$ can usually be leached with water (Arroyo and Fernández-Pereira, 2008; Font et al., 2005). The obtained aqueous leach solution from the leaching step is usually treated in a hydrometallurgical process to separate germanium from other impurities such as molybdenum, nickel, zinc and other heavy metals (Arroyo and Fernández-Pereira, 2008). Among hydrometallurgical processes, solvent extraction (SX) is a promising separation technique due to its high efficiency and flexibility.

Anion exchange and solvation extractants such as amines and phosphine oxides can be useful to separate anionic/neutral species from impurities in mixed solutions. In the current study, Alamine 336, Aliquat 336, and Cyanex 923 were used to separate germanium from aqueous solutions containing heavy metals. Alamine 336 (tri-octyl/decyl amine) is an extractant with the anionic exchange mechanism, which can form organic complexes with anionic species. Anionic species such as molybdenum $\left(\mathrm{MoO}_{2}{ }^{-4}, \mathrm{HMoO}^{-4}\right.$, and $\left.\mathrm{Mo}_{7} \mathrm{O}_{24}{ }^{-6}\right)$ (Morís et al., 1999), cobalt $\left(\mathrm{CoCl}_{4}{ }^{2-}\right.$ and $\left.\mathrm{CoCl}^{3-}\right)$ (Filiz et al., 2006), chromium(VI) $\left(\mathrm{CrO}_{3} \mathrm{SO}_{4}{ }^{2-}\right.$ and $\left.\mathrm{HCrO}_{4}{ }^{-}\right)$(Bachmann et al., 2010) and platinum $\left(\mathrm{PtCl}_{4}{ }^{-2}\right)$ (Reddy et al., 2010) have been effectively extracted by Alamine 
336 at acidic pHs. Some extractants with a similar composition to Alamine 336 such as N235 (tri(octyl/decyl) amine) and TOA (tri(octyl) amine) have been used to extract germanium from aqueous solutions. A SX process was developed to extract germanium and gallium anionic species from aqueous solutions of the zinc refinery residue leaching step using N235 mixed with TBP (Liu et al., 2017). The mentioned process was based on complexing germanium species with oxalates to form anionic oxalate-germanium complexes $\left(\left[\mathrm{Ge}\left(\mathrm{C}_{2} \mathrm{O}_{4}\right)_{3}\right]^{2-}\right)$ which could be extracted by $\mathrm{N} 235$, i.e. an anion exchange extractant. Furthermore, Arroyo and FernándezPereira (2008) extracted germanium-catechol anionic species $\left(\left[\mathrm{Ge}\left(\mathrm{C}_{6} \mathrm{H}_{4} \mathrm{O}_{2}\right)_{3}\right]^{2-}\right)$ from an aqueous solution of the GCFA leaching step by TOA. In addition, Aliquat 336 as an ionic liquid in the form of $\mathrm{R}_{4} \mathrm{~N}^{+} \mathrm{Cl}^{-}$can react with anionic species because its positive ammonium side can bind to various anions in a broad $\mathrm{pH}$ range (Nayl, 2010). In a study, thenoyltrifluoroacetone (HTTA) was used to form anionic species of lanthanides $\left(\left[\operatorname{Ln}(\operatorname{TTA})_{4}\right]^{-}\right)$followed by extraction using Aliquat 336 (Atanassova et al., 2002). Aliquat 336 was reported as an efficient extractant to recover various anionic species such as chromium(III) $\left(\mathrm{Cr}(\mathrm{OH})_{4}\right)$ (Wionczyk et al., 2006), iron $\left(\mathrm{FeCl}_{4}{ }^{-}\right)$(Mishra et al, 2011), mercury(II) $\left(\mathrm{HgCl}_{3}{ }^{-}\right.$and $\left.\mathrm{HgCl}_{4}{ }^{-}\right)$, zinc(II), and cadmium(II) $\left(\left[\mathrm{ZnCl}_{4}\right]^{2-}\right.$ and $\left[\mathrm{CdCl}_{4}\right]^{2-}$ ) (Wassink et al., 2000) from industrial effluents (Fábrega and Mansur, 2007; Mishra et al., 2011; Salazar et al., 1992; Wassink et al., 2000). Germanium-citrate anionic species $\left(\mathrm{Ge}(\mathrm{OH})_{2}(\mathrm{Cit})^{-}\right)$could be extracted using $0.1 \mathrm{~mol} / \mathrm{L}$ Aliquat 336 followed by stripping using a $0.5 \mathrm{~mol} / \mathrm{L} \mathrm{HCl}$ solution (Sahoo, 1991; Vibhute and Khopkar, 1986). Furthermore, Cyanex 923 with the solvation mechanism, comprising four trialkyl phosphine oxides, is employed in extensive SX processes. Neutral species of scandium(III) $\left(\mathrm{HSc}\left(\mathrm{SO}_{4}\right)_{2}\right)$ ( $\mathrm{Li}$ and Wang, 1998), lanthanum(III) $\left(\mathrm{Ln}\left(\mathrm{NO}_{3}\right)_{3}\right)$ (Gupta et al, 2003), titanium(IV) $\left(\mathrm{TiCl}_{4}\right)$ (Saji John et al., 1999), cadmium(II) $\left(\mathrm{CdCl}_{2}\right)$ (Gupta et al., 2001; Reddy and Priya, 2006), gold(III) $\left(\mathrm{HAuCl}_{4}\right)$ 
(Martínez et al., 1996), $\mathrm{TiCl}_{4}, \mathrm{VCl}_{4}, \mathrm{HFeCl}_{4}, \mathrm{CuCl}_{2}$, and $\mathrm{ZnCl}_{2}$ (Gupta et al., 2002), $\mathrm{LA}(\mathrm{SCN})_{3}$ (LA shows trivalent lanthanides) (Reddy et al., 1998), vanadium $\left(\mathrm{VO}_{2} \mathrm{Cl}\right)$ (Remya et al., 2003), praseodymium $\left(\operatorname{Pr}\left(\mathrm{NO}_{3}\right)_{3}\right)$, and samarium $\left(\mathrm{Sm}\left(\mathrm{NO}_{3}\right)_{3}\right)$ (El-Nadi, 2010) can be extracted by Cyanex 923 from various aqueous solutions. Furthermore, Gupta and Mudhar (2006) reported that $\mathrm{GeCl}_{4}$ could be formed in a concentrated $\mathrm{HCl}$ solution $(8 \mathrm{M})$ followed by extraction using Cyanex 923.

As seen in the aforementioned discussion, few studies investigated the solvent extraction of germanium using Alamine 336, Aliquat 336, and Cyanex 923 extractants. Hence, in this research, the comparative solvent extraction of germanium was investigated using the aforementioned extractants. Two of these extractants are amine extractants (anion exchanger) and the third is a phosphine oxide with the solvation mechanism. The effect of extractant concentrations, complexant concentration, and strip phase composition was converted investigated and compared for each extractant. Finally, the efficiencies and performances of each extractant were compared and a proper extractant was chosen.

\section{Experimental and Methods}

\subsection{Materials}

Alamine 336 was purchased from Cognis (part of BASF), Germany containing tri C8-10 alkyl amines with a molecular weight of $353.67 \mathrm{~g} / \mathrm{mol}$ and density of $0.818 \mathrm{~g} / \mathrm{cm}^{3}$. The protonated molecules of Alamine 336 should be prepared to extract anionic species. Hence, diluted hydrochloric acid was used to protonate Alamine 336 molecules. The related reaction can be presented as Eq. (1):

$\mathrm{R}_{3} \mathrm{~N}_{(\mathrm{org})}+\mathrm{HCl}_{(\mathrm{aq})}=\left[\mathrm{R}_{3} \mathrm{NH}\right]^{+}\left[\mathrm{Cl}^{-}{ }^{-}\right.$(org) 
Alamine 336 (a formula weight of 353.67 , specific gravity of 0.81 , viscosity of $34.8 \mathrm{mPa}$ at 34.6 ${ }^{\circ} \mathrm{C}$, and purity of $95.0-100.0 \%$ ) provided by Cognis Deutschland $\mathrm{GmbH}$, Germany is an anionic exchanger used to extract anionic species. Another extractant used in the current study was an ionic liquid extractant namely tri-capryloyl methyl ammonium chloride (Aliquat 336) purchased from Alfa Aesar Co., Germany. Aliquat 336 has a formula weight of 404.17, specific gravity of 0.88 , viscosity of $1500 \mathrm{mPa}$ at $30{ }^{\circ} \mathrm{C}$, and purity of $88.2-93.0 \%$. In order to convert germanium (the target element in this study) to an anionic complex, a complexant was used, namely tartaric acid from Merck, Germany. The converted species were in the form of $\mathrm{Ge}(\mathrm{OH})_{2}\left(\mathrm{C}_{4} \mathrm{H}_{4} \mathrm{O}_{6}\right)^{2-}$ which were extractable by aforementioned amine extractants (Pokrovski and Schott, 1998). In addition, an organophosphorus extractant called Cyanex 923 composed of four trialkylphosphine oxides with a composition of $93 \%$, specific gravity of 0.88 , formula weight of 348 , specific gravity of 0.88 , and viscosity of $40.0 \mathrm{mPa}$ at $25{ }^{\circ} \mathrm{C}$ was provided by Cytec Inc., USA. In order to produce the neutral species that can be extracted with the solvation mechanism by Cyanex 923, oxalic acid was used from Merck, Germany. In this regard, trisoxalato germinates were produced as shown in Eq. (2) (Liu et al., 2017):

$$
3 \mathrm{H}_{2} \mathrm{C}_{2} \mathrm{O}_{4}+\mathrm{GeO}_{2} \cdot \mathrm{H}_{2} \mathrm{O} \Leftrightarrow \mathrm{H}_{2} \mathrm{Ge}\left(\mathrm{C}_{2} \mathrm{O}_{4}\right)_{3}+3 \mathrm{H}_{2} \mathrm{O}
$$

Dilutes of extractants used in this study were kerosene and 1-decanol purchased from SigmaAldrich and Merck, respectively. The solutions used in experiments were prepared by dissolving the powders of $\mathrm{GeO}_{2}(99.999 \%), \mathrm{ZnSO}_{4} .7 \mathrm{H}_{2} \mathrm{O}(\geq 99.0 \%), \mathrm{CdSO}_{4}(\geq 99.0 \%), \mathrm{CoSO}_{4} . \mathrm{H}_{2} \mathrm{O}$ ( $\geq 99.0 \%), \mathrm{NiSO}_{4} \cdot 6 \mathrm{H}_{2} \mathrm{O}(99.0-102.0 \%)$ (Aldrich A.C.S. Reagent) in pure distilled water (with the neutral $\mathrm{pH}$ of 6.5 ). The composition of solutions was $100 \mathrm{mg} / \mathrm{L} \mathrm{Ge}, \mathrm{Ni}, \mathrm{Cd}$, and $\mathrm{Co}$ as well as $1000 \mathrm{mg} / \mathrm{L} \mathrm{Zn}$. After dissolving tartaric acid in solutions, the $\mathrm{pH}$ descended to about 3-3.2 depending on the concentration of tartaric acid. In addition, the $\mathrm{pH}$ of solutions containing 
mentioned ions in the presence of oxalic acid was in the range of 1-3 with respect to the concentration of oxalic acid. The composition of the mentioned synthetic solutions was similar to that obtained after water leaching of gasification coal fly ashes containing germanium.

\subsection{Procedure}

Solvent extraction experiments were conducted by shaking an equal volume of aqueous and organic phases $(5 \mathrm{~mL})$ for $15 \mathrm{~min}$ by a shaker (SBS Instruments SA, Spain) in separating funnels at room temperature. After $15 \mathrm{~min}$ and achieving equilibrium state, two phases were separated in mentioned funnels. The concentrations of germanium and the other ions in the aqueous phases were determined by inductively coupled plasma optical emission spectroscopy (ICP-OES; Agilent, USA). In order to determine the ion concentrations in loaded organic phases, the mass balance calculation was carried out. The extraction/stripping efficiency was calculated by dividing the concentration of loaded/stripped ions to that of the initial solution before treating. Furthermore, the distribution coefficient (D) was the ratio of the ion concentration of the organic phase to that of the aqueous phase under equilibrium state. The separation factor was determined by dividing the distribution coefficient of germanium to that of the other ions.

\section{Results and Discussion}

\subsection{Effect of extractant concentrations}

To investigate the effect of extractant concentration on the germanium extraction efficiency and its separation from zinc, nickel, cadmium, and cobalt, a series of experiments was conducted at 
various concentrations of Alamine 336 (in the range of 0 to $40 \% \mathrm{v} / \mathrm{v}$ ), Aliquat 336 (in the range of 0 to $2 \% \mathrm{v} / \mathrm{v}$ ), and Cyanex 923 (in the range of 0 to $30 \% \mathrm{v} / \mathrm{v}$ ). The extraction efficiency of the elements versus the concentration of extractants is shown in Fig. 1. As mentioned, the concentrations of germanium, zinc, nickel, cadmium, and cobalt in the feed solution were 100 $\mathrm{mg} / \mathrm{L}$ and the amount of zinc was $1000 \mathrm{mg} / \mathrm{L}$. In order to convert germanium species to anionic complexes, an amount of $0.00276 \mathrm{~mol} / \mathrm{L}$ tartaric acid $(2$ times the germanium molar concentration) was added to feed solutions. As shown in this figure, with increasing the concentration of Alamine 336 from $0.25 \%$ to $30 \%$, the germanium extraction efficiency increases from about $2 \%$ to $100 \%$. The germanium extraction efficiency approached $100 \%$ when the Alamine 336 concentration increased up to $10 \% \mathrm{v} / \mathrm{v}$. On the other hand, with an enhancement of Aliquat 336 concentration up to $0.2 \%$, the germanium extraction efficiency reached about $100 \%$. Since the extraction of other metal ions by Alamine 336 and Aliquat 336 is negligible, they were not illustrated in Fig. 1. The reason for this behavior is the lack of the anionic/neutral complex formation between these elements and tartaric/oxalic acids, respectively. Furthermore, an increase of the Cyanex 923 concentration resulted in enhancing the germanium extraction efficiency, as after reaching the concentration of Cyanex 923 to $20 \% \mathrm{v} / \mathrm{v}$, the extraction efficiency tended to be $100 \%$. It is noteworthy that due to the instability of heavy metals-oxalates in this study, solvent extraction experiments were conducted on germanium oxalate solutions obtained after filtering solid precipitates. Consequently, according to Fig. 1, the germanium extraction efficiency corresponding to Aliquat 336 reached a maximum value in much lower concentrations, whereas the maximum extraction was achieved at about $15-20 \% \mathrm{v} / \mathrm{v}$ for Alamine 336 and Cyanex 923. 


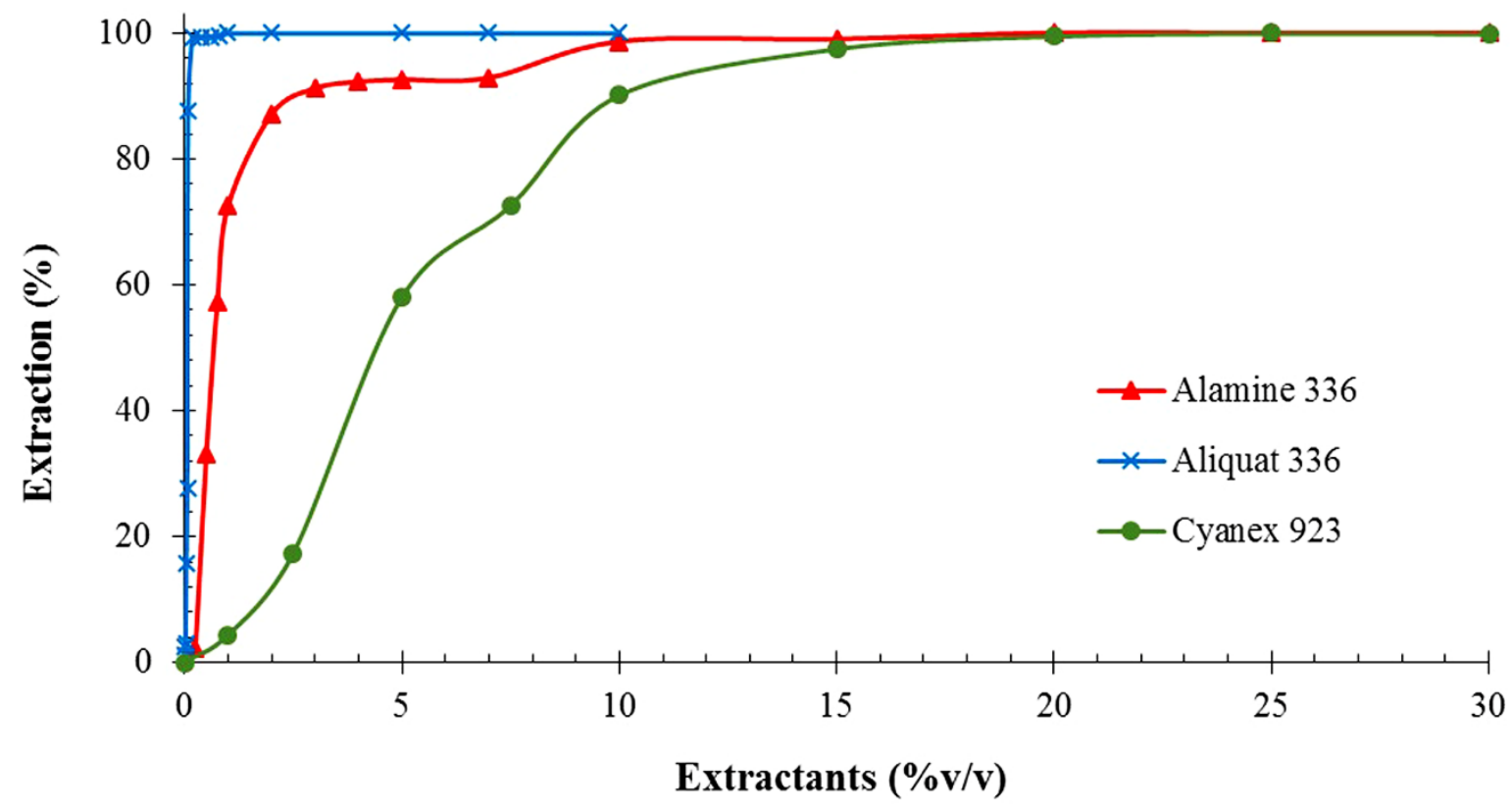

Fig. 1. Effect of extractant concentration on germanium extraction efficiency.

In order to examine the number of extractant molecules reacted with germanium species, $\log \mathrm{D}$ versus $\log$ [extractant] was plotted followed by plotting trend lines for Alamine 336, Aliquat 336, and Cyanex 923. The corresponding result is illustrated in Fig. 2. As seen in this figure, $\log$ D enhances linearly with increasing $\log [$ extractant]. The slopes of the trend lines show the rate of this increase. As a result, the slopes close to 2, 3, and 4 were obtained for Alamine 336, Aliquat 336, and Cyanex 923, respectively. It is noted that despite the value of 2.70 obtained for the Aliquat 336 slope analysis, the value of 2 is common for Aliquat 336 molecules in the literature (Bhatluri et al., 2014; Wei et al, 2016). Thus, the value of 2 was a better choice in this case. Therefore, the corresponding extraction reactions can be proposed as Eqs. (3), (4), and (5) for Alamine 336, Aliquat 336, and Cyanex 923, respectively. In the following reactions, $\mathrm{R}_{3} \mathrm{NHCl}$, $\mathrm{R}_{4} \mathrm{NCl}$, and $\mathrm{L}_{\mathrm{org}}$ denote the molecules of Alamine 336, Aliquat 336, and Cyanex 923, respectively. In addition, $\mathrm{T}$ shows tartrate replaced with $\mathrm{C}_{4} \mathrm{H}_{4} \mathrm{O}_{6}{ }^{2-}$. 
$2\left(\mathrm{R}_{3} \mathrm{NHCl}\right)_{(\text {org })}+\mathrm{Ge}(\mathrm{OH})_{2} \mathrm{~T}^{2-}{ }_{(a q)} \Leftrightarrow\left(\mathrm{R}_{3} \mathrm{NH}\right)_{2} \mathrm{Ge}(\mathrm{OH})_{2} T_{(o r g)}+2 \mathrm{Cl}^{-}{ }_{(a q)}$

$2\left(R_{4} \mathrm{NCl}\right)_{(o r g)}+\mathrm{Ge}(\mathrm{OH})_{2} \mathrm{~T}^{2-}{ }_{(a q)} \Leftrightarrow\left(R_{4} \mathrm{~N}\right)_{2} \mathrm{Ge}(\mathrm{OH})_{2} T_{(o r g)}+2 \mathrm{Cl}^{-}{ }_{(a q)}$

$\mathrm{H}_{2} \mathrm{Ge}\left(\mathrm{C}_{2} \mathrm{O}_{4}\right)_{3,(a q)}+4 L_{(o r g)} \Leftrightarrow \mathrm{H}_{2} \mathrm{Ge}\left(\mathrm{C}_{2} \mathrm{O}_{4}\right)_{3} \cdot 4 L_{(o r g)}$

In Eqs. (3) and (4), germanium tartrates are extracted based on the anionic mechanism, whereas in Eq. (5), germanium carboxylates and Cyanex 923 are reacted together based on the solvation mechanism.

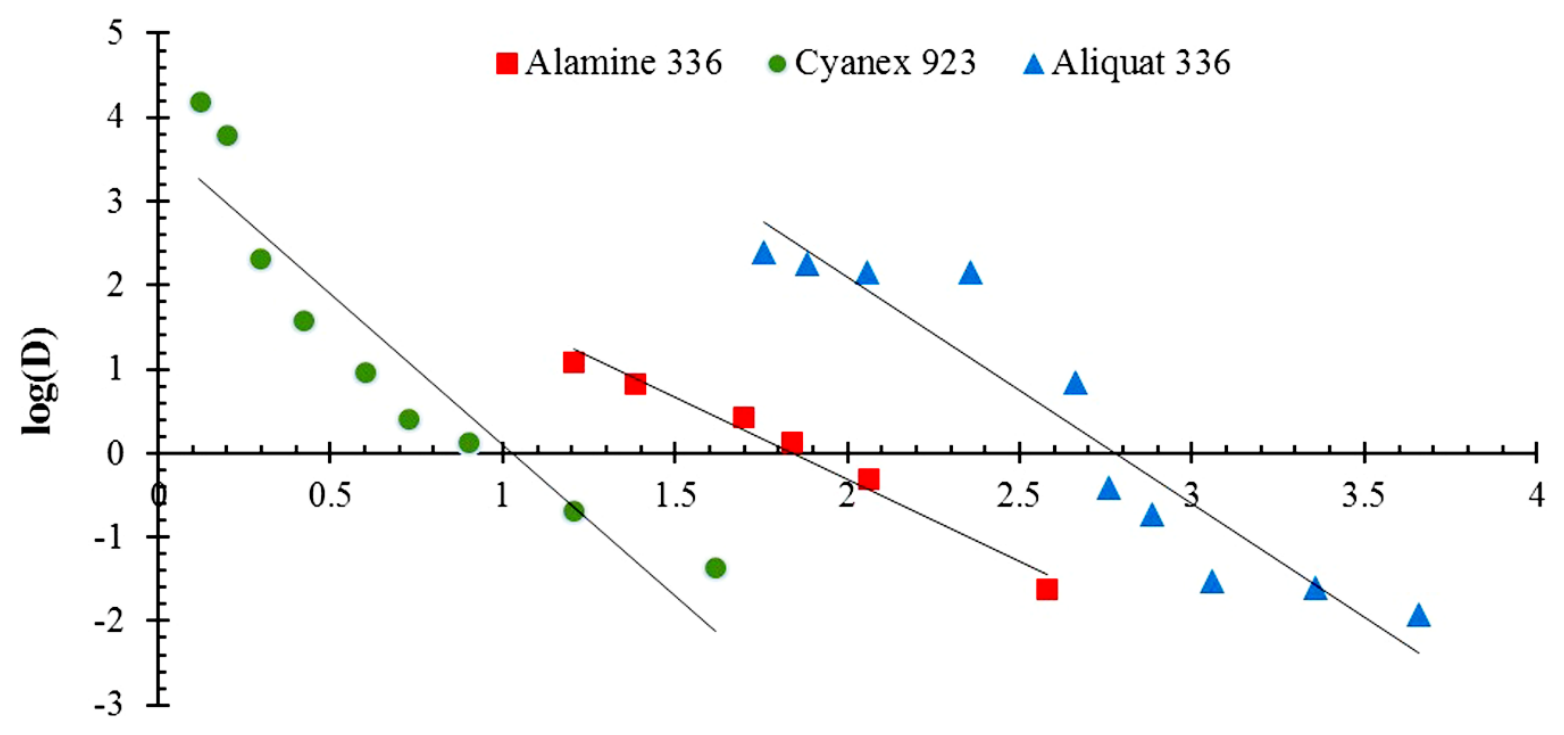

$-\log [$ Cyanex 923]

Fig. 2. Slope analysis for determining the number of extractant molecules reacted with germanium species.

\subsection{Effect of complexant}


One of the ways for the selective separation of germanium from an aqueous mixed solution is to produce it anionic species, which can be extracted by amine extractants. In this regard, a number of complexants, which were expected to form an anionic complex with germanium, were examined in solvent extraction experiments. Tartaric acid, citric acid, oleic acid, and catechol were selected for these experiments. Fig. 3 illustrates the effect of these complexes on the germanium extraction efficiency. With respect to the powerful affinity of Aliquat 336 toward anionic species, this extractant was selected to compare the aforementioned complexants. As shown in this figure, in the presence of tartaric acid and citric acid, all germanium species were extracted by Aliquat 336 with the concentration of $1 \% \mathrm{v} / \mathrm{v}$. The results of the solvent extraction experiment in the presence of citric/tartaric acids $\left(\mathrm{C}_{6} \mathrm{H}_{8} \mathrm{O}_{7} / \mathrm{C}_{4} \mathrm{H}_{6} \mathrm{O}_{6}\right)$ showed that the complexation of germanium and these types of acids resulted in forming germanium citrate/tartrate anions that can be completely extracted by Aliquat 336. However, the results corresponding to oleic acid $\left(\mathrm{C}_{18} \mathrm{H}_{34} \mathrm{O}_{2}\right)$ showed that Aliquat 336 could not extract germanium. This can be due to two probabilities: (a) a lack of the germanium complex formation (positive, negative or neutral) between germanium and oleic acid, and (b) a lack of germanium anionic complexes. This issue can be attributed to the long hydrocarbon chain of oleic acid. Catechol $\left(\mathrm{C}_{6} \mathrm{H}_{6} \mathrm{O}_{2}\right)$ is another reagent used to form germanium anionic species. The germanium extraction efficiency of $85 \%$ was observed in the presence of catechol. In a research published in 2009, a hydrometallurgical method was used to extract germanium from a solution containing germanium and catechol [20]. In that study, the complexation of germanium with catechol in the aqueous solution was first performed and then the germanium-catechol complexes $\left(\mathrm{Ge}\left(\mathrm{C}_{6} \mathrm{H}_{4} \mathrm{O}_{2}\right)_{3}{ }^{2-}\right)$ were extracted with TOA (tri-octylamine). 


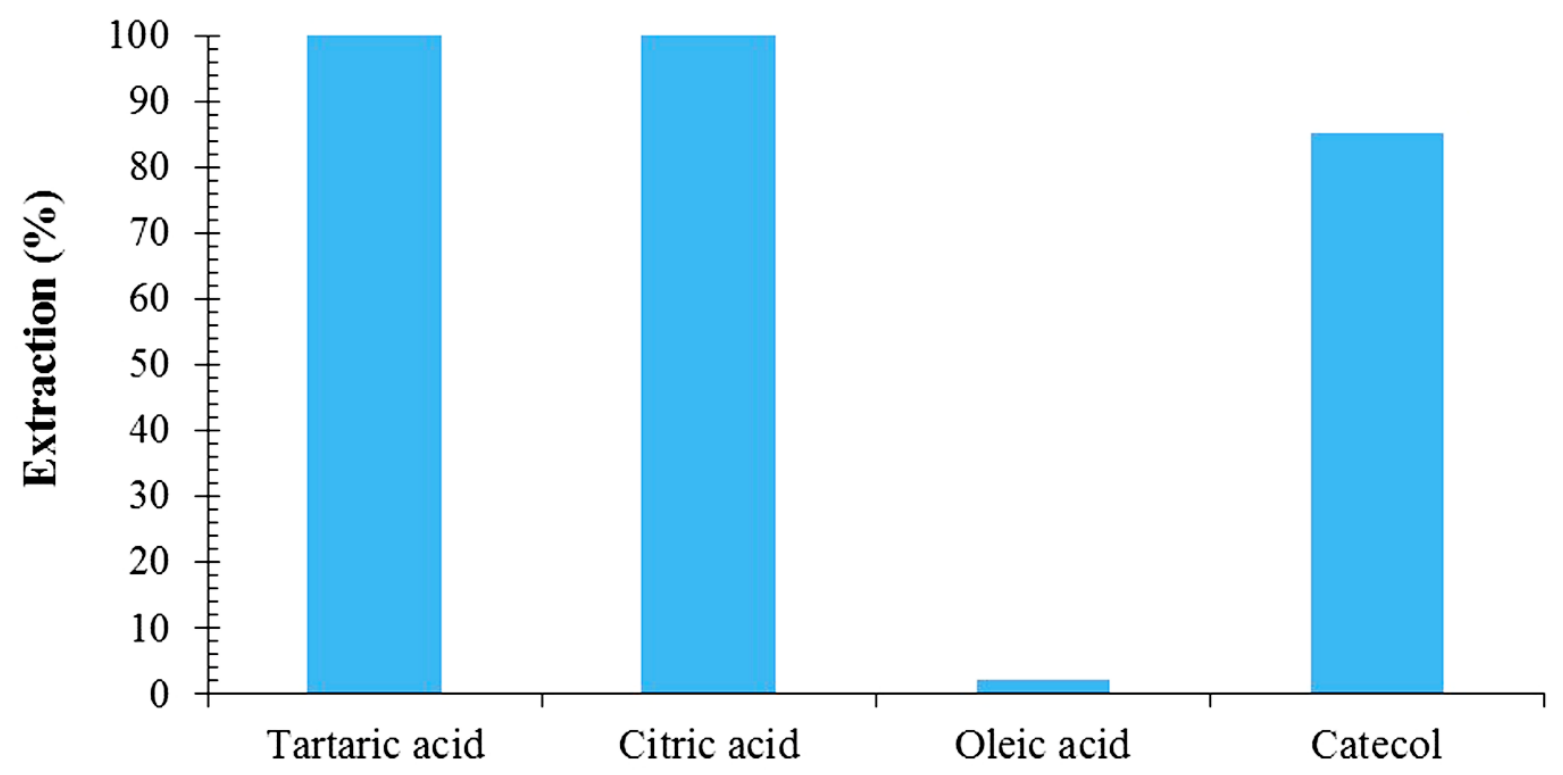

Fig. 3. Effect of the type of complexants on germanium extraction efficiency

One of the important factors influencing the extraction of germanium by amine extractants is the presence of tartaric acid. The absence of this complexant is equivalent to the absence of extractable anionic species, which can halt the extraction processes. As shown in Fig. 4, in the absence of tartaric acid, no germanium species have been extracted. By increasing the concentration of tartaric acid up to 1 time the mole ration of tartaric acid to Ge in the solution, the germanium extraction efficiency increases up to $60 \%$ and $86 \%$ for Alamine 336 and Aliquat 336, respectively. The extra addition of tartaric acid up to 2 times (the mole ration of tartaric acid to $\mathrm{Ge}$ ) for Alamine 336 and Aliquat 336 systems resulted in extracting more than $97 \%$ of germanium from solutions. Therefore, the minimum amount of tartaric acid required for the complete reaction of germanium ions with tartrate complexes was $0.00275 \mathrm{M}$ (2 times the mole ration of tartaric acid to $\mathrm{Ge}$ ). By the excess addition of tartaric acid, there was an insignificant change in the extraction efficiency. Consequently, the optimal amount of tartaric acid is 2 times the mole ration of tartaric acid to Ge. It is noteworthy that due to the low extraction efficiencies 
of other metals, which were close to 0 , the corresponding results were not shown in the figure. The reason for the selective extraction of germanium over heavy metals can be recognized using stability constants of ions-tartrates. Table 1 listed the stability constants (Ks) of heavy metalsand germanium- tartrates. As seen in this table, the value of $\log (\mathrm{Ks})$ corresponding to the germanium-tartrate is higher than those belonging to heavy metals-tartrates, indicating that the proportion of germanium tartrate anionic species is the highest.

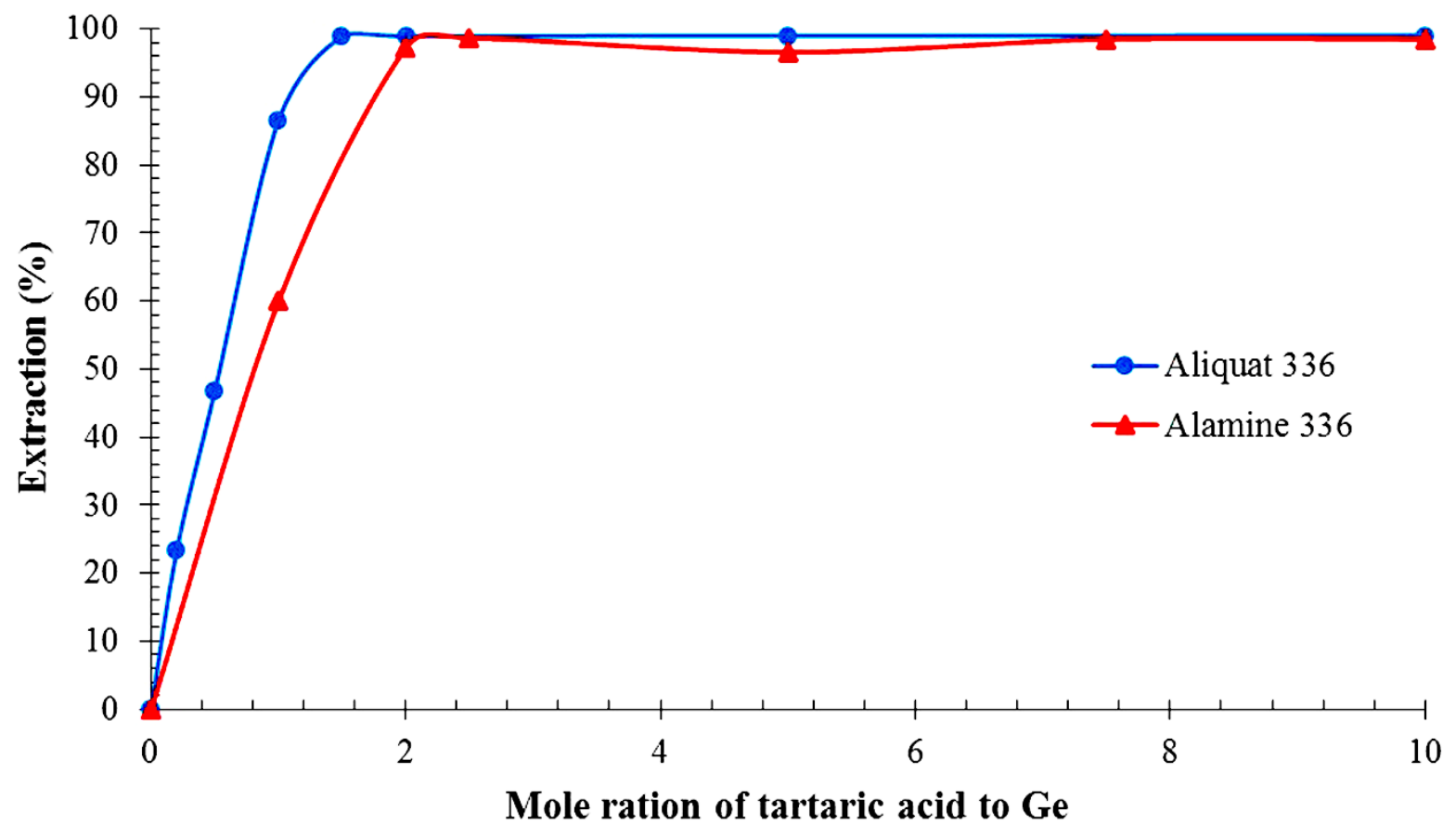

Fig. 4. Effect of tartaric acid on the extraction efficiency of germanium 
Table 1. Stability constants of metals-tartrate and -oxalate

\begin{tabular}{|c|c|c|c|c|}
\hline & Logarithm & f stability constant $(\operatorname{logKs})$ & & \\
\hline Element & Tartrate $^{\mathrm{a}}$ & Reference & Oxalate $^{b}$ & Reference \\
\hline $\mathrm{Zn}$ & 2.39 & $\begin{array}{c}\text { (Alumaa and Pentchuk, } \\
\text { 1998) }\end{array}$ & Very low & (Sobel et al., 2008) \\
\hline $\mathrm{Ni}$ & 2.32 & $\begin{array}{c}\text { (Alumaa and Pentchuk, } \\
\text { 1998) }\end{array}$ & low & (Dalton et al., 2016) \\
\hline $\mathrm{Cd}$ & 2.27 & (Lin and Horváth, 1992) & & (Dalton et al., 2016) \\
\hline $\mathrm{Co}$ & 2.26 & $\begin{array}{c}\text { (Alumaa and Pentchuk, } \\
\text { 1998) }\end{array}$ & Very low & (Dalton et al., 2016) \\
\hline $\mathrm{Ge}$ & 31.51 & $\begin{array}{l}\text { (Pokrovski and Schott, } \\
\text { 1998) and calculations }\end{array}$ & 9.89 & $\begin{array}{c}\text { (Pokrovski and Schott, 1998) } \\
\text { and calculations }\end{array}$ \\
\hline
\end{tabular}

(a) Ionic strength of tartrate solution $=0.3$

(b) Ionic strength of oxalate solution $=0.5$

As mentioned before, oxalic acid is vital for the solvation extraction of germanium by Cyanex 923. Therefore, the effect of the oxalic acid concentration on the germanium extraction efficiency was investigated. As seen in Table 1, heavy metals-oxalate stability constants are very low. This means that these species are unstable and precipitated in oxalate solutions. These precipitates have been seen in the experiments and the chemical analysis of filtered solutions confirmed this instability. Therefore, further solvent extraction experiments by Cyanex 923 were carried out after separating precipitates from germanium oxalate solutions. As shown in Fig. 5, the absence of oxalic acid resulted in no extraction of germanium species. By increasing the concentration of oxalic acid up to $0.1 \mathrm{M}$ in the feed solution, the extraction approaches $85 \%$. According to the results, the concentration of oxalic acid required for the complete formation of 
germanium-oxalate species was determined to be $0.1 \mathrm{M}$. This efficiency reached $100 \%$ by adding more than $0.1 \mathrm{M}$ oxalic acid.

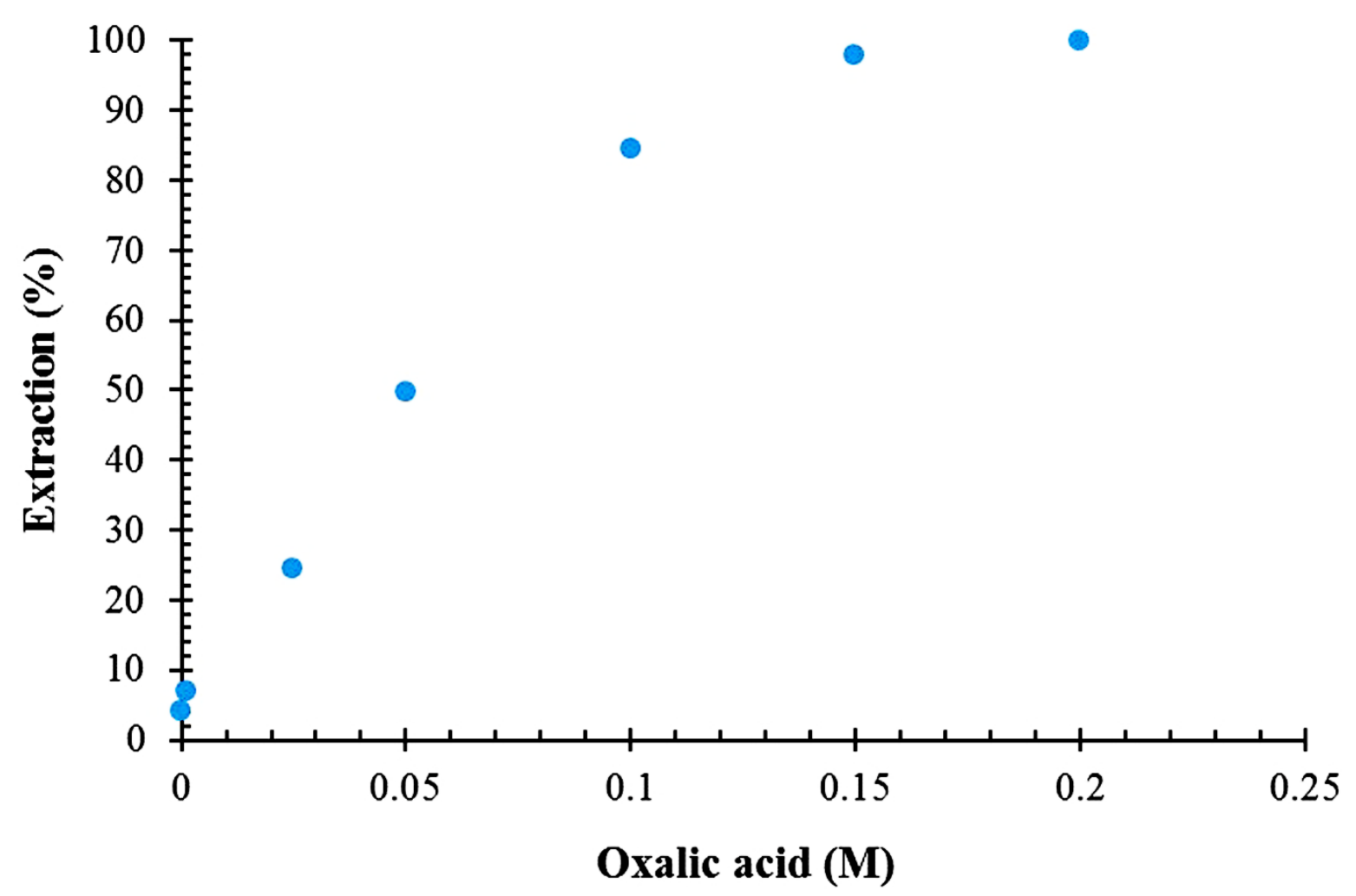

Fig. 5. Effect of oxalic acid on the germanium extraction efficiency in the solvent extraction of germanium by Cyanex 923 .

\subsection{Effect of strippant and its concentration on germanium extraction}

In order to strip germanium from organic phases, Alamine 336 and Aliquat 336 extractants were prepared with concentrations of $10 \% \mathrm{v} / \mathrm{v}$. These extractants were mixed with a solution containing $100 \mathrm{mg} / \mathrm{L} \mathrm{Ge}$ and $0.00273 \mathrm{M}$ tartaric acid to extract all germanium species. Mineral acids have shown good ability to strip germanium from amine extractants (Arroyo and Fernández-Pereira, 2008; Sahoo, 1991). In this study, $\mathrm{HCl}$ was used in different concentrations for germanium stripping. Fig. 6 shows the effect of $\mathrm{HCl}$ concentration on stripping of germanium 
and the other elements. As shown in this figure, by increasing the concentration of acid up to 1 M, the germanium stripping efficiency from Alamine 336 increased up to $98 \%$, whereas at this concentration, the stripping efficiency from Aliquat 336 reached about $78 \%$. The minimum $\mathrm{HCl}$ concentration for $98 \%$ stripping of germanium from Alamine 336 and Aliquat 336 was 1 and 1.5 M, respectively. However, unlike the Alamine 336 system, the germanium stripping in the Aliquat system approached $99 \%$ at $2 \mathrm{M} \mathrm{HCl}$. After the mentioned concentrations, the stripping efficiency reached a straight line for both of the extractants. The stripping efficiency of other elements was also negligible. The Ge stripping reactions corresponding to Alamine 336 and Aliquat 336 can be written as Eqs. (6) and (7), respectively. It is noteworthy that at acidic pHs, germanium species are converted to $\mathrm{Ge}(\mathrm{OH})_{2}(\mathrm{HT})^{-}$(Pokrovski and Schott, 1998).

$$
\left(\mathrm{R}_{3} \mathrm{NH}\right)_{2} \mathrm{Ge}(\mathrm{OH})_{2} \mathrm{~T}_{(\mathrm{org})}+2 \mathrm{Cl}^{-}{ }_{(a q)}+\mathrm{H}^{+} \Leftrightarrow 2\left(\mathrm{R}_{3} \mathrm{NHCl}\right)_{(\text {org })}+\mathrm{Ge}(\mathrm{OH})_{2}(\mathrm{HT})^{-}{ }_{(a q)}
$$

$$
\left(\mathrm{R}_{4} \mathrm{~N}\right)_{2} \mathrm{Ge}(\mathrm{OH})_{2} \mathrm{~T}_{(\mathrm{org})}+2 \mathrm{Cl}_{(\mathrm{raq})}^{-}+\mathrm{H}^{+} \Leftrightarrow 2\left(\mathrm{R}_{4} \mathrm{NCl}\right)_{(\mathrm{org})}+\mathrm{Ge}(\mathrm{OH})_{2}(\mathrm{HT})^{-}{ }_{(a q)}
$$




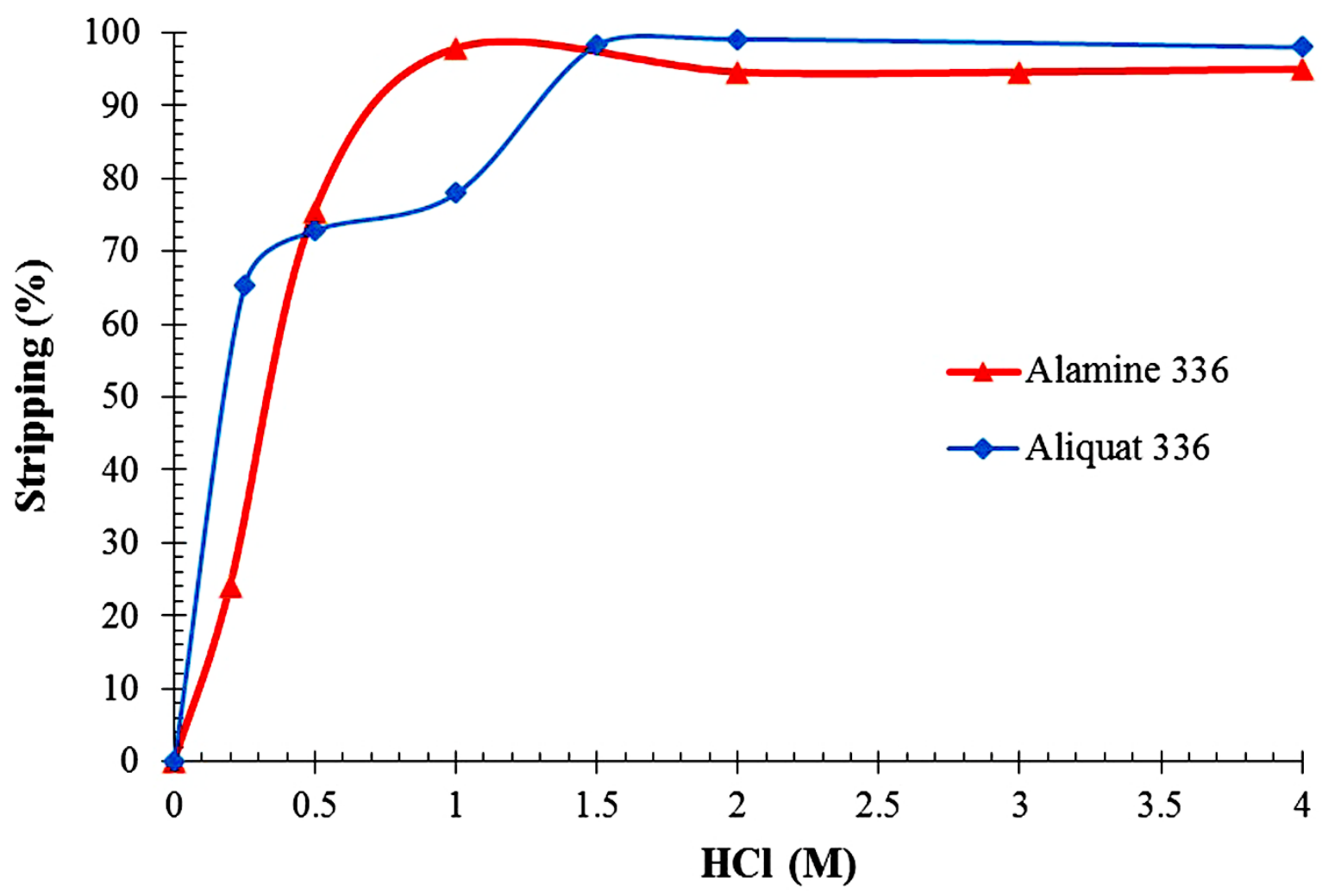

Fig. 6. Effect of $\mathrm{HCl}$ concentration on stripping efficiencies of germanium from Alamine 336 and Aliquat 336.

In order to strip germanium from loaded Cyanex 923, a series of solvent extraction experiments was conducted to select proper chemicals. In this regard, several chemical reagents that were expected to be useful for the stripping process were selected. These included ammonium chloride $\left(\mathrm{NH}_{4} \mathrm{Cl}\right)$, sodium hydroxide $(\mathrm{NaOH})$, catechol $\left(\mathrm{C}_{6} \mathrm{H}_{6} \mathrm{O}_{2}\right)$, citric acid $\left(\mathrm{C}_{6} \mathrm{H}_{8} \mathrm{O}_{7}\right)$, ammonia $\left(\mathrm{NH}_{3}\right)$, sodium sulfate $\left(\mathrm{Na}_{2} \mathrm{SO}_{4}\right)$, and sulfuric acid $\left(\mathrm{H}_{2} \mathrm{SO}_{4}\right)$. Concentrations and stripping efficiencies corresponding to these reagents have been shown in Table 2. 
Table 2. Effect of strippant type on stripping efficiency of germanium

\begin{tabular}{|c|c|c|}
\hline Reagent & $\begin{array}{c}\text { Concentration, } \\
M\end{array}$ & Strip efficiency (\%) \\
\hline $\mathrm{NH}_{4} \mathrm{Cl}$ & 0.1 & 3.04 \\
\hline $\mathrm{NH}_{3}$ & 0.1 & Decomposition of strip reagent \\
\hline $\mathrm{NaOH}$ & 0.1 & 91.70 \\
\hline $\mathrm{C}_{6} \mathrm{H}_{6} \mathrm{O}_{2}$ & 0.1 & 5.27 \\
\hline $\mathrm{C}_{6} \mathrm{H}_{8} \mathrm{O}_{7}$ & 0.1 & 15.92 \\
\hline $\mathrm{Na}_{2} \mathrm{SO}_{4}$ & 0.1 & 9.30 \\
\hline $\mathrm{H}_{2} \mathrm{SO}_{4}$ & 0.1 & 1 \\
\hline
\end{tabular}

As shown in Table 2, $\mathrm{NaOH}$ is an effective chemical reagent for germanium stripping from Cyanex 923. In several studies, $\mathrm{NaOH}$ has been used as a stripping material in solvent extraction and liquid membrane systems using Cyanex 923 (Agrawal et al., 2008; Nosrati et al., 2011). Therefore, to study the germanium stripping from the organic phase, a volume of Cyanex 923 was prepared with a concentration of $10 \% \mathrm{v} / \mathrm{v}$, by which germanium was extracted from a solution containing $0.15 \mathrm{M}$ oxalic acid. This loaded organic phase was used in stripping experiments. Fig. 7 shows the effect of $\mathrm{NaOH}$ concentration on the germanium stripping efficiency. As shown in this figure, by increasing the concentration of $\mathrm{NaOH}$ up to $0.1 \mathrm{M}$, the germanium stripping efficiency reached a constant value of $92 \%$. Hence, the concentration of 0.1 M was chosen as an optimal condition. The Ge stripping from Cyanex 923 can be shown as Eq. (8):

$$
\mathrm{H}_{2} \mathrm{Ge}\left(\mathrm{C}_{2} \mathrm{O}_{4}\right)_{3} \cdot 4 L_{(\text {org })}+2 \mathrm{OH}^{-} \Leftrightarrow 4 L_{(\text {org })}+\mathrm{Ge}\left(\mathrm{C}_{2} \mathrm{O}_{4}\right)_{3}{ }^{2-}+2 \mathrm{H}_{2} \mathrm{O}
$$




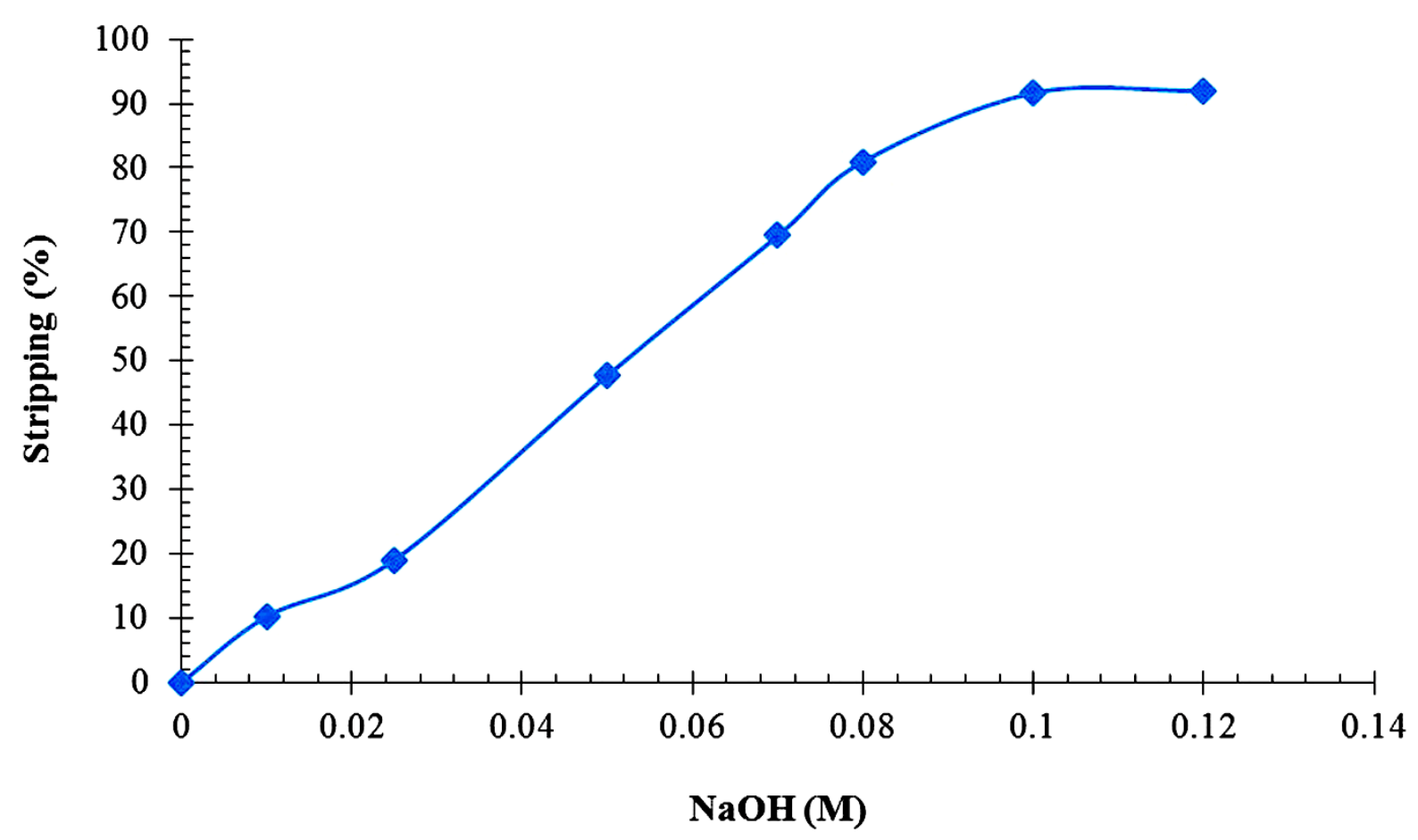

Fig. 7. Effect of $\mathrm{NaOH}$ concentration on stripping efficiency of germanium from Cyanex 923.

\section{Conclusion}

In the current study, the comparative solvent extraction of germanium in the presence of nickel, cadmium, and cobalt was investigated. The composition of the mentioned synthetic solution was similar to that obtained after water leaching of gasification coal fly ashes containing germanium. The effect of extractant, complexant, and strippant concentrations was examined. The results showed that germanium extraction corresponding to Aliquat 336 reached a maximum value in much lower concentrations, whereas the maximum extraction was achieved at about 15-20\%v/v for Alamine 336 and Cyanex 923. Furthermore, the results showed that in the absence of appropriate complexants, the formation of anionic species (extractable by amine extractants) and solvated species (extractable by Cyanex 923) was not possible and the extraction process was halted. In this regard, the effect of tartaric acid and oxalic acid as complexants on the germanium 
extraction by Alamine 336, Aliquat 336 as well as Cyanex 923 was investigated. According to the results, the ratio of 2 (mole ration of tartaric acid to $\mathrm{Ge}$ ) was selected as an optimum concentration for the complete extraction of germanium by Alamine 336 and Aliquat 336. Furthermore, the oxalic acid concentration of $0.1 \mathrm{M}$ was sufficient for the reaction of germanium species with Cyanex 923. In order to strip germanium from amine extractants, $\mathrm{HCl}$ was used. As a result, the concentrations of 1 and $2 \mathrm{M}$ were selected as an optimum condition for stripping of germanium from Alamine 336 and Aliquat 336, respectively. Among the reagents examined for germanium stripping from Cyanex 923, $\mathrm{NaOH}$ was the best for stripping. Consequently, the concentration of $0.1 \mathrm{M}$ was selected as an optimum condition for stripping of germanium from Cyanex 923. With respect to the results, it can be concluded that Aliquat 336 was the best extractant for germanium extraction because, at much lower concentrations, all germanium species were extracted. Furthermore, a smaller amount of complexant (tartaric acid) was required in amine solvent extraction systems in comparison to the Cynaex 923 system. In addition, from an industrial view, an acidic solution is more logical than a caustic reagent in a strip process.

\section{Acknowledgements}

This research was performed in the Department of Chemical Engineering, Universitat Politècnica de Catalunya (Barcelona-Tec), Vilanova i la Geltrú Campus, Spain. The authors thank all staffs and Dr. Maria Teresa Coll for their assistance and scientific consultants.

\section{References}

Agrawal, A., Pal, C. and Sahu, K.K., 2008. Extractive removal of chromium (VI) from industrial waste solution. Journal of Hazardous Materials, 159(2-3): 458-464.

Alumaa, P. and Pentchuk, J., 1998. Ionic strength dependence of heavy metal tartrate complex stabilities. Chromatographia, 47(1): 77-80.

Arroyo, F. and Fernández-Pereira, C., 2008. Hydrometallurgical recovery of germanium from coal gasification fly ash. Solvent extraction method. Industrial \& Engineering Chemistry Research, 47(9): 3186-3191. 
Arroyo, F. et al., 2009. Germanium and gallium extraction from gasification fly ash: optimisation for upscaling a recovery process, World of Coal Ash Conference. Avaible at: http://www. flyash. info.

Atanassova, M., Jordanov, V.M. and Dukov, I.L., 2002. Effect of the quaternary ammonium salt Aliquat 336 on the solvent extraction of lanthanoid (III) ions with thenoyltrifluoroacetone. Hydrometallurgy, 63(1): 41-47.

Bachmann, R.T., Wiemken, D., Tengkiat, A.B. and Wilichowski, M., 2010. Feasibility study on the recovery of hexavalent chromium from a simulated electroplating effluent using Alamine 336 and refined palm oil. Separation and Purification Technology, 75(3): 303-309.

Bhatluri, K.K., Manna, M.S., Saha, P. and Ghoshal, A.K., 2014. Supported liquid membrane-based simultaneous separation of cadmium and lead from wastewater. Journal of Membrane Science, 459: 256-263.

Dalton, G.R., Lee, A.Y. and Young, S.L., 2016. IUPAC/NIST Solubility Database. IUPAC/NIST Solubility Database.

Depuydt, B. et al., 2007. Chapter 1 - Germanium Materials, Germanium-Based Technologies. Elsevier, Oxford, pp. 11-I.

El-Nadi, Y.A., 2010. Effect of diluents on the extraction of praseodymium and samarium by Cyanex 923 from acidic nitrate medium. Journal of Rare Earths, 28(2): 215-220.

Fábrega, F.d.M. and Mansur, M.B., 2007. Liquid-liquid extraction of mercury (II) from hydrochloric acid solutions by Aliquat 336. Hydrometallurgy, 87(3): 83-90.

Filiz, M., Sayar, N.A. and Sayar, A.A., 2006. Extraction of cobalt(II) from aqueous hydrochloric acid solutions into alamine 336-m-xylene mixtures. Hydrometallurgy, 81(3): 167-173.

Font, O. et al., 2005. Ge extraction from gasification fly ash. Fuel, 84(11): 1384-1392.

Gupta, B., Deep, A. and Malik, P., 2001. Extraction and recovery of cadmium using Cyanex 923. Hydrometallurgy, 61(1): 65-71.

Gupta, B., Deep, A., Malik, P. and Tandon, S.N., 2002. Extraction and separation of some 3d transition metal ions using Cyanex 923. Solvent Extraction and Ion Exchange, 20(1): 81-96.

Gupta, B., Malik, P. and Deep, A., 2003. Solvent extraction and separation of tervalent lanthanides and yttrium using Cyanex 923. Solvent Extraction and Ion Exchange, 21(2): 239-258.

Gupta, B. and Mudhar, N., 2006. Extraction and separation of germanium using Cyanex 301/Cyanex 923. its recovery from transistor waste. Separation Science and Technology, 41(3): 549-572.

Harbuck, D.D., Judd, J.C. and Behunin, D.V., 1991. Germanium solvent extraction from sulfuric acid solutions (and co-extraction of germanium and gallium). Solvent Extraction and Ion Exchange, 9(3): 383-401.

Li, D. and Wang, C., 1998. Solvent extraction of scandium(III) by Cyanex 923 and Cyanex 925. Hydrometallurgy, 48(3): 301-312.

Lin, F.H.-J. and Horváth, C., 1992. Measurement of stability constants for complexes of divalent cations with tartaric acid by ion chromatography. Journal of Chromatography A, 589(1): 185-195.

Liu, F. et al., 2017. Recovery and separation of gallium(III) and germanium(IV) from zinc refinery residues : Part II: Solvent extraction. Hydrometallurgy, 171: 149-156.

Martínez, S., Sastre, A., Miralles, N. and Alguacil, F.J., 1996. Gold(III) extraction equilibrium in the system Cyanex 923-HCl-Au(III). Hydrometallurgy, 40(1): 77-88.

Mishra, R.K., Rout, P.C., Sarangi, K. and Nathsarma, K.C., 2011. Solvent extraction of Fe(III) from the chloride leach liquor of low grade iron ore tailings using Aliquat 336. Hydrometallurgy, 108(1): 93-99.

Morís, M.a.A., Díez, F.V. and Coca, J., 1999. Solvent extraction of molybdenum and tungsten by Alamine 336 and DEHPA in a rotating disc contactor. Separation and Purification Technology, 17(3): 173179. 
Nayl, A.A., 2010. Extraction and separation of $\mathrm{Co}(\mathrm{II})$ and $\mathrm{Ni}(\mathrm{II})$ from acidic sulfate solutions using Aliquat 336. Journal of Hazardous Materials, 173(1-3): 223-230.

Nosrati, S., Jayakumar, N.S. and Hashim, M.A., 2011. Extraction performance of chromium (VI) with emulsion liquid membrane by Cyanex 923 as carrier using response surface methodology. Desalination, 266(1-3): 286-290.

Nusen, S., Zhu, Z., Chairuangsri, T. and Cheng, C.Y., 2015. Recovery of germanium from synthetic leach solution of zinc refinery residues by synergistic solvent extraction using LIX 63 and lonquest 801. Hydrometallurgy, 151: 122-132.

Pokrovski, G.S. and Schott, J., 1998. Experimental study of the complexation of silicon and germanium with aqueous organic species: implications for germanium and silicon transport and $\mathrm{Ge} / \mathrm{Si}$ ratio in natural waters. Geochimica et Cosmochimica Acta, 62(21): 3413-3428.

Reddy, B.R. and Priya, D.N., 2006. Chloride leaching and solvent extraction of cadmium, cobalt and nickel from spent nickel-cadmium, batteries using Cyanex 923 and 272. Journal of Power Sources, 161(2): 1428-1434.

Reddy, B.R., Raju, B., Lee, J.Y. and Park, H.K., 2010. Process for the separation and recovery of palladium and platinum from spent automobile catalyst leach liquor using LIX $84 \mathrm{I}$ and Alamine 336. Journal of Hazardous Materials, 180(1): 253-258.

Reddy, M.L.P., Luxmi Varma, R., Ramamohan, T.R., Sahu, S.K. and Chakravortty, V., 1998. Cyanex 923 as an extractant for trivalent lanthanides and yttrium. Solvent Extraction and Ion Exchange, 16(3): 795-812.

Remya, P.N., Saji, J. and Reddy, M.L.P., 2003. Solvent Extraction and separation of vanadium (v) from multivalent metal chloride solutions by Cyanex 923. Solvent Extraction and Ion Exchange, 21(4): 573-589.

Sahoo, S.K., 1991. Reversed phase extraction chromatographic separation of germanium with Aliquat 3365 from Citric Acid. Bulletin of the Chemical Society of Japan, 64(8): 2484-2487.

Saji John, K., Saji, J., Reddy, M.L.P., Ramamohan, T.R. and Rao, T.P., 1999. Solvent extraction of titanium(IV) from acidic chloride solutions by Cyanex 923. Hydrometallurgy, 51(1): 9-18.

Salazar, E., Ortiz, M.I., Urtiaga, A.M. and Irabien, J.A., 1992. Equilibrium and kinetics of chromium(VI) extraction with Aliquat 336. Industrial \& Engineering Chemistry Research, 31(6): 1516-1522.

Sobel, S., Haigney, A., Concepcion, T. and Kim, M., 2008. The complexation of aqueous metal ions relevant to biological applications. 1. Poorly soluble zinc salts and enhanced solubility with added amino acid. Chemical Speciation \& Bioavailability, 20(2): 93-97.

Vibhute, C.P. and Khopkar, S.M., 1986. Solvent Extraction Separation of Germanium with Aliquat 336S from Citric Acid Solutions. Bulletin of the Chemical Society of Japan, 59(10): 3229-3232.

Wassink, B., Dreisinger, D. and Howard, J., 2000. Solvent extraction separation of zinc and cadmium from nickel and cobalt using Aliquat 336, a strong base anion exchanger, in the chloride and thiocyanate forms. Hydrometallurgy, 57(3): 235-252.

Wei, W. et al., 2016. Selective recovery of $\mathrm{Au}(\mathrm{III}), \mathrm{Pt}(\mathrm{IV})$, and $\mathrm{Pd}(\mathrm{II})$ from aqueous solutions by liquidliquid extraction using ionic liquid Aliquat-336. Journal of Molecular Liquids, 216: 18-24.

Wionczyk, B., Apostoluk, W. and Charewicz, W.A., 2006. Solvent extraction of chromium (III) from spent tanning liquors with Aliquat 336. Hydrometallurgy, 82(1): 83-92. 
Highlights

- Ge(IV) was selectively separated from impurities by solvent extraction.

- Germanium extraction by Alamine 336, Aliquat 336, and Cyanex 923 was compared.

- Composition of treated solution was similar to fly ash leachate.

- The best extractant was Aliquat 336. 